\title{
Regional inflation dynamics and its persistence - The case of selected regions in Indonesia
}

\author{
Haryo Kuncoro It is difficult to say whether adopting inflation \\ Faculty of Economics, targeting leads to converged regional inflation \\ State University of Jakarta, rates. This paper observes the dynamics of \\ Indonesia regional inflation rate in the case of three \\ E-mail: har_kun@feunj.ac.id \\ selected cities (Medan, Jakarta, and Makassar) \\ in Indonesia during the regional autonomy \\ and fiscal decentralisation era. We used \\ monthly inflation rates data between January \\ 2001 and December 2018 to achieve this. We \\ found that there is no significant difference \\ between regional and national inflation rates. \\ However, the inflation rate differences occurs \\ both between-months within a year and \\ between-months across years. The speed of \\ adjustment is found to be unchanged after \\ the adoption of inflation targeting. It seems \\ that inflation targeting fails to reduce the \\ volatility of inflation rates both at the regional \\ and national levels. Since the regional \\ Keywords: \\ regional inflation, \\ persistency, \\ inflation targeting, \\ speed of adjustment \\ inflation rate is typically generated by supply- \\ side, those results suggest that managing \\ inter-region cooperation in the supply-chain \\ will stabilise and reduce the national inflation \\ rate.
}

\section{Introduction}

Over the last two decades, inflation targeting (IT) has become the dominant monetary policy regime both in developed and emerging economies (Svensson 1999, 2000, Kocziszky et al. 2018). Following the Asian crisis of 1997-1998, some countries in Asia, like Korea, Thailand, the Philippines and Indonesia, adopted IT. The monetary policy is directed to achieve and maintain inflation at low and stable rates.

While the successful adoption of IT both in both developed and emerging countries for the purpose of maintaining stable inflation rate is well documented, the effectiveness of IT in reducing persistent inflation fluctuations has been inconclusive. The IT that may reduce the persistence of inflation fluctuations is typically derived from aggregate inflation or sectoral inflation rates. However, the opposite conclusion is based on regional inflation data.

Regional Statistics, Vol. 10. No. 2. 2020: 95-116; DOI: 10.15196/RS100211 
The high regional inflation rates contribute to the high persistent national inflation. However, the co-movements and heterogeneity in inflation rates at regional and national levels have not been analysed systematically so far (Beck et al. 2006). This makes it difficult for the monetary authority to address the issue as the characteristics of regional inflation differ from region to region. Accordingly, the implementation of monetary policies in order to address inflation at the national level may be ineffective in the regional context (Mehrotra et al. 2007).

Furthermore, the effectiveness of the response to shocks depends on its persistence on inflation. Inflation persistence is sometimes defined as the tendency of price shocks to push the inflation rate away from its steady-state, including an IT, for a prolonged period. The degree of persistence may have a negative sign meaning that inflation moves in the opposite direction as in the previous period, referring to a correction process. However, over shorter periods, various macroeconomic shocks temporarily move inflation away from its long-run trend. The effects of these shocks on inflation can be persistent and lead to persistent deviations of the level of inflation from its mean representing price stability.

Allocation, stabilisation and distribution are the other regional political-economic issues consistent with fiscal decentralisation. Price stabilisation is a prerequisite achieving equal income distribution across the region. Most developing countries in the world fail to maintain prices (Prud'homme 1995). Moreover, at the early periods of decentralisation, they suffered unequal regional income distribution (SepulvedaMartinez-Vazquez 2010). Hence, reconsidering issues arising from regional price stabilisation will encourage the central bank in emerging markets to reduce inflation volatility by adopting an active monetary policy.

Recognising the inflation persistence at the regional level is critical. For policymakers, deviations of the inflation rate, the speed of reaction of implementing correction measures, and the output cost of implementation determine the different types of policies. For academics, the underlying dynamics of inflation and how the theory fits the facts are crucial. In developing countries, such persistence would have important policy implications including domestic stabilisation policy, poverty reduction, inequities in wealth distribution and growth, and the development implications thereof (Alagidede et al. 2014).

Indonesia is a good case study for this investigation. In a country as geographically diverse as Indonesia, studying inflation persistence, particularly at the regional level is useful from a monetary policy point of view. The institutional differences among regions may not be fully reflected in aggregate output and inflation trends. Differences in inflation persistence might be reflective of the structural rigidities (Zsibók 2017) that could reduce each region's capacity to adjust to shocks and the corresponding policy responses.

In the context of fiscal policy, since 2001, Indonesia has been transforming itself into the most decentralised country in the world (Alm et al. 2001). Accordingly,

Regional Statistics, Vol. 10. No. 2. 2020: 95-116; DOI: 10.15196/RS100211 
some economic tasks have been devolved to the local governments including price stabilisation. Furthermore, since July 2005, Indonesia has adopted an IT regime. The policies are directed to achieve the goal of monetary policy by stabilising the inflation and the currency exchange rates.

Also, coordinated by the Central Bank of Indonesia, the local governments are involved in the Regional Inflation Controlling Task Force (RITF), to ensure stable and lower regional inflation rates. Inflation is a monetary phenomenon where a demand-pull factor is dominant, while some studies emphasise that the supply side factors influence regional inflation in developing countries (Hossain 1996, Mohanty-Klau 2001, Brodjonegoro 2004, Hakkio 2009).

Local governments have more knowledge and information on the sources and factors of inflation in their respective regions, and they have the authority to allocate fiscal resources and coordinate other resources, including local policies or regulations to support stable and low level inflation. Price stability is part of the local government task in Indonesia in an effort to improve public welfare. Therefore, we analyse the behaviour of the regional dynamics of the inflation rate and its persistence. Lessons from Indonesia, which implemented the IT frameworks ahead of the fiscal decentralisation policy, will be useful to develop a better design of the inflation rates' stabilisation policy for developing countries.

This paper studies the regional dimension of IT; that is, the consequences of IT for regional inflation persistence. Understanding the dynamic patterns of inflation is a crucial issue for modern economies as it impacts economic efficiency and wealth. We focus on Medan (the capital of North Sumatera), Jakarta (the capital of Indonesia), and Makassar (the capital of South Sulawesi) as the case study to understand regional inflation. The remainder of this paper is organised as follows. The next section explores the literature and related empirical studies. The research method is explained in the third section, followed by the results and discussion. Finally, some concluding remarks are drawn.

\section{Literature review}

The concern about inflation is usually at the national level while the attention in the regional level is relatively rare. This is because there is no established theoretical framework that considers inflation differences between regions within a country. Therefore, knowledge of regional inflation developments is limited. Nevertheless, existing studies can be classified into two groups. The first is based on the theory of purchasing power parity and the second refers to the hedonic price theory.

The earlier analysis of the regional inflation rate is covered in the price differential proposition. The prominent idea in this regard is the law of one price and purchasing power parity (Rogoff 1996, Krugman-Obstfeld 2000). The conventional demand and supply interaction across the region equalises the price

Regional Statistics, Vol. 10. No. 2. 2020: 95-116; DOI: 10.15196/RS100211 
levels. Accordingly, price levels across the region are relatively equal and, therefore, there is no substantial regional price or inflation rate differential.

Recent economic studies analyse the regional dynamic inflation and price convergence. In this framework, the higher price level regions tend to grow slower than that of the lower price level regions. As in the growth convergence (BarroSala-i-Martin 1995), the price levels and inflation rates converge and eventually tend to be equal across the region. The assumption behind these two propositions is free mobility either input or output which are rarely met in the real world.

Another strand of literature tries to explain why price convergence does not take place. Price disparity might be associated with the rigidities in wages or exchange rates (Becker 2011). Any factor that prevents the nominal exchange rates and wages from adjusting in response to an economic shock could be a reason for inflation differentials (Becker 2011). Finally, asymmetric economic shocks can change either the demand or the supply conditions in different countries and can cause dispersed price movements (Weber 2004, Tunay-Silpagar 2007).

The divergence of prices could be related to the hedonic price theory. The hedonic price theory proposes that certain socio-economic regional characteristics form the prices in a region. It means that prices represent the value of quality. Different regions have their socio-economic characteristics. Consequently, price differentials exist. Consistent with regionalism and globalisation in the last two decades, the theory of the hedonic prices has become a popular mathod to explain regional inflation rate differentials worldwide.

The Balassa-Samuelson effect is another way to study regional inflation differences (Balassa 1964, Samuelson 1964). It suggests that an increase in wages in the tradable goods sector of an emerging region leads to higher wages in the nontradable (service) sector of the economy. The accompanying increase in prices makes inflation rates higher in faster-growing regions than in slow-growing or developed regions. It implies that the optimal rate of inflation will be higher for developing regions as they grow and raise their productivity.

Furthermore, the idea of an optimal currency area (Mundell 1961) can be adopted to explain the regional inflation dynamics. The theory speculates that there is an optimum geopolitical area which should share a currency. An integrated labour market allows workers to move freely throughout the area and smooth out unemployment in any single zone. The flexibility of pricing and wages, along with the mobility of capital, would eliminate regional trade imbalances. The wealthy parts of the region may wish to distribute their surpluses among those that have no such oversupplies. As a result, regional price differences converge.

Recent studies have been directed to discuss these issues. Beck, Hubrich, and Marcellino (2006) observed the regional inflation dynamics within the euro area and the US. They found that the disaggregate regional inflation information, summarised by the area-wide factors is important in explaining aggregate euro area and US

Regional Statistics, Vol. 10. No. 2. 2020: 95-116; DOI: 10.15196/RS100211 
inflation rates, even after conditioning on macroeconomic variables. Therefore, monitoring regional inflation rates within the euro area provides relevant additional information for the monetary policymakers.

Vaona (2008) and Vaona and Ascari (2012) considered a sample of 70 Italian regions in a single country. The two studies go beyond the assumption that there exists a unique core inflationary process in a macro-economy. They show that the local long-run inflation rates can display remarkable variability. On the one hand, they are negatively correlated with productivity growth. On the other hand, the less competitive is the local retail sector, the higher is a long-run inflation.

In the case of emerging countries, Tillmann (2013) based on data for Korean cities and provinces showed that the adoption of IT leads to (i) a fall in inflation persistence at the regional level; and (ii) a reduction in the cross-regional heterogeneity in inflation persistence. A factor model lends further support to the role of the common component and the monetary policy for regional inflation persistence.

Danvee and Basilio (2009) analysed the regional inflation persistence in the Philippines using uni-variate models of inflation as well as panel unit-root tests and applied these tests to regional headline inflation between 1989 and 2008. They found that inflation in the individual regions reverts to the long-run path after a shock. The regional inflation rates tend to converge toward the cross-sectional mean in the long run except during periods of generalised shocks. In such cases, underlying cross-sectional factors (e.g., geography, income development, among others) could be playing an important role in the regions' inflation processes. They also found that food price inflation appears to have a relatively lesser persistence.

In the case of India, Kundu, Kishore, and Bhoi (2018) reveals the presence of wide dispersion in inflation across states, largely driven by food price inflation. State-level inflation tends to converge with the national average over time. However, it validates the choice of national-level consumer price inflation as the nominal anchor for monetary policy in India. These findings underpin the choice of the national-level consumer price index inflation as the nominal anchor under India's flexible IT framework.

In the case of Indonesia, Arimurti and Trisnanto (2011) measured the persistence of inflation level in Jakarta. Their study intended to find out the source of inflation persistence and its implication on regional inflation control. The analysis of regional inflation behaviour is explored at the commodities level. The empirical result indicates that the level of inflation persistence in Jakarta is relatively high, and stems from a high level of inflation persistence for most of the commodities that construct inflation. Their study is consistent with Winkelried and Gutierrez (2015) who studies the case of Lima, Peru.

Tirtosuharto and Adiwilaga (2013) conducted an empirical analysis to determine the effect of decentralisation on regional inflation in Indonesia and whether

Regional Statistics, Vol. 10. No. 2. 2020: 95-116; DOI: 10.15196/RS100211 
institutions play a role in the recent downward trend of inflation in Indonesia as a whole. A panel data that includes 33 observations of the Indonesian regions (provinces) is constructed with a dummy variable representing the existence of an institution. In addition this study analyses whether decentralisation supports the convergence in regional inflation and also the pattern of spatial correlation in regional inflation. This paper finds that decentralisation has an impact on regional inflation in Indonesia, where an increase in the degree of fiscal decentralisation also increases the volatility of regional inflation.

Kusuma (2013) employed disaggregated data on inflation combined with Factor Augmented Vector Auto Regression to explore the price behaviour in Indonesia. The main finding of this analysis is that price behaviour in Indonesia exhibits heterogeneity. This is evident not only in terms of the magnitude but also in the direction and the speed of adjustment to the new equilibrium in response to interest rate shock. Price volatility is mainly related to sector-specific shocks instead of macroeconomic shocks. Another finding is that price puzzle weakens once IT framework is adopted.

Purwono, Tasin, and Mubin (2020) investigated the inflation convergence of 82 Indonesian cities and discussed the remarkable regional inflation programmes in Indonesia. By employing a dynamic panel data regression, they show that Indonesia experienced an inflation convergence from 2013 to 2018. An intriguing finding is that the cities in Java-Bali, the densest area, experienced a slower speed of convergence than that in cities outside the Java-Bali.

Based on the above empirical studies, the link between regionalism and decentralisation with inflation as one of the key aspects of macroeconomic stability is generally inconclusive. However, decentralisation correlates with lower inflation in developed countries and vice versa. Its correlation with higher inflation in developing countries has received conventional wisdom. Hence, the remaining issues to be considered are as follows. First, the most common measure of inflation persistence suggested in the literature is based on a uni-variate time-series model that assumes an auto-regressive process. Second, inflation persistence that is measured as the sum of the autoregressive coefficients is time varying. Third, the performance of the expected inflation rates, i.e. backward- or forward-looking behaviour types. Forth, the time perspective has to be covered.

Our study deals primarily with the last issue. We contribute to the literature in three aspects. First, unlike other studies that draw a comparison between regions within the country, our regional analysis is related to the national inflation rates. Regional inflation rates in general are poorly synchronised with national inflation rates (Hakkio 2009, Ciccarelli-Mojon, 2010, Auer et al. 2017). Second, the study will use analysis of variance (ANOVA) to evaluate the dynamics of regional inflation rates from an inter-month and inter-year perspective in the regional autonomy and fiscal decentralisation era. We also compare them in the pre- and post-IT adoption.

Regional Statistics, Vol. 10. No. 2. 2020: 95-116; DOI: 10.15196/RS100211 
Third, our study uses a city instead of a province as the unit of analysis. The use of the smallest administrative area in calculating inflation reduces the aggregation bias.

\section{Research method}

ANOVA is used to investigate whether there is a mean difference between three or more population groups. Here, we use a two-way ANOVA because we analyse two factors, within-variation and between-variation. Variance is the squared differences of values and its averages, which is derived from the differences of total average and column or row average. The first variance is the total sum of squares (SST). The second variance is the sum of square columns (SSC) and the sum of square rows (SSR). The differences between each value and its total mean value $(\bar{X})$ squared, give us the SST.

$$
S S T=\sum_{i=1}^{a} \sum_{j=1}^{b}\left(X_{i j}-\bar{X}\right)^{2}
$$

Through the differences between each column values and the mean of that column $\left(\bar{X}_{i}\right)$, we obtain SSC, and the same logic is applied to obtain the SSR $\left(\bar{X}_{j}\right)$.

$$
S S C=a \sum_{i=1}^{a}\left(\bar{X}_{i}-\bar{X}\right)^{2}
$$

Therefore, the sum of the square error (SSE) is the difference between SST and the two variances obtained.

$$
\text { SSE }=\text { SST }- \text { SSC }- \text { SSR }
$$

Each variance value must be corrected by its degree of freedom. The SST value is divided by $\mathrm{N}-1$, the SSC value is divided by (a-1), and SSR value is divided by $(\mathrm{b}-1)$, and SSE value is divided by $[(\mathrm{a}-1) \mathrm{x}(\mathrm{b}-1)]$. At this stage, ANOVA is run by comparing column and row variances with undefined variances:

$$
\begin{aligned}
& F \operatorname{stat}(1)=\frac{S S C /(a-1)}{\operatorname{SSE} /[(a-1) x(b-1)]} \\
& F \operatorname{stat}(2)=\frac{S S R /(b-1)}{\operatorname{SSE} /[(a-1) x(b-1)]}
\end{aligned}
$$

$\mathrm{N}=$ number of data; $\mathrm{a}=$ number of columns; $\mathrm{b}=$ number of rows

The inequality of differences in the time frame, monetary regime, and unit analysis are evaluated by using multivariate analysis of variance (MANOVA). MANOVA is simply an ANOVA with several dependent variables. Thus, ANOVA tests for the difference in means between two or more groups, while MANOVA tests for the difference in two or more vectors of means.

MANOVA can be used to investigate the dimensions on which the groups differ. Next, we examine the effects of independent variables (IV) across several dependent measures. MANOVA can be used to examine all the DVs at the same

Regional Statistics, Vol. 10. No. 2. 2020: 95-116; DOI: 10.15196/RS100211 
time. Additionally, MANOVA controls Type 1 error (the probability of rejecting the null hypothesis when it is true) across all the DVs in the model.

The generic model of MANOVA can be written as:

$$
X_{i j}=\mu+\tau_{i}+\varepsilon_{i j}
$$

where $\mathrm{X}$ is the vector of observation, $\mu$ is the mean, $\tau$ is the treatment, and $\varepsilon$ is the error term for $i=1,2,3, \ldots, n$ and $j=1,2,3, \ldots, m$.

The vector of observation can be decomposed once again as follows:

$$
X_{i j}=\bar{X}+\left(\bar{X}_{i}-\bar{X}\right)+\left(\bar{X}_{i j}-\bar{X}_{i}\right)
$$

where the first term on the right-hand side is the grand mean, the second term is the effect of treatment, and the last is the residual.

A multivariate analysis of variance tests the null hypothesis against the alternative hypothesis:

$$
\begin{gathered}
H_{0}: \tau_{1}=\tau_{2}=\cdots=\tau_{k}=0 \\
H_{a}: \tau_{1} \neq \tau_{2} \neq \cdots \neq \tau_{k} \neq 0
\end{gathered}
$$

Instead of a uni-variate $F$ value, we obtain a multivariate $F$ value (Wilks' $\lambda$ ) based on a comparison of the error and the effect variance or covariance matrices. Other statistics may be used, including Hotelling's trace, Pillai-Bartlet's criterion, and Roy's largest root.

Unlike multiple ANOVA, MANOVA accounts for the co-variances of the other dependent variables, which could increase statistical power. Thus, MANOVA has the potential to be a more powerful test than uni-variate ANOVA because it considers both the variances and covariances of the dependent measures.

The 'co-variance' is included here because the two measures are probably correlated and we must consider this correlation when performing the significance test. Testing the multiple dependent variables is accomplished by creating new dependent variables that maximise group differences. These artificial dependent variables are linear combinations of the measured dependent variables.

The general assumptions for MANOVA design are (1) independence of subject responses in each between-subjects condition; (2) multivariate normal dependent measures in the population; and (3) equality of population variance-covariance matrices in groups defined by between-subjects factors. Additionally, the multivariate approach to repeated measures does not require the sphericity assumption (Tabachnick-Fidell 2007).

Neither ANOVA nor MANOVA can identify the degree of persistence. The inflation persistence and speed of adjustment are measured by testing using a univariate approach. The uni-variate auto-regression process is represented as follows:

$$
P_{t}=\alpha+P_{t-1}+\varepsilon_{t}
$$

where $\mathrm{P}=$ consumer price index and $\varepsilon=$ random disturbance error term.

$$
Z_{t} \equiv \operatorname{Inf} f_{t}=\frac{P_{t}}{P_{t}-P_{t-1}} \approx \Delta \log P_{t}
$$




$$
Z_{t}=\alpha+\sum_{1}^{j} \beta_{j} Z_{t-j}+\epsilon_{t}
$$

where $Z=$ inflation series at time $t$ (measured as month-on-month growth of consumer price index) and $\epsilon=$ random disturbance error term.

To observe the degree of persistence in terms of the sum of AR coefficients, equation (9) may be re-written as

$$
Z_{t}=\alpha+\rho Z_{t-1}+\sum_{1}^{j} \beta_{j} \Delta Z_{t-j}+\epsilon_{t}
$$

The persistence parameter $\tau$ of an inflation time series is computed as the sum of the coefficients from the estimated uni-variate $\mathrm{AR}(\mathrm{k})$ time series model. It is interpreted as the speed with which inflation goes back to its equilibrium value after a shock. To reiterate, it represents the time it takes to fully dissipate the effect of a one percent rise in inflation due to a shock. Similarly, equation (10) may be expressed in a different form

$$
\Delta Z_{t}=\alpha+\phi Z_{t-1}+\sum_{1}^{j} \beta_{j} \Delta Z_{t-j}+\epsilon_{t}
$$

which is a basic ADF specification to test for the presence of a unit-roots and where $\phi=(\rho-1)$.

The ADF procedure tests the null hypothesis that the process has a unit-root $(\rho=1)$. When $\rho=1$, the inflation series is a random walk, non-stationarity, and therefore highly persistent because of the autocorrelation with its lags. Shocks will tend to have long-lasting effects on the behaviour of the series and may take a long time to converge back to its long-run equilibrium or may even diverge from its longrun path permanently.

Willis (2003) defines $\rho$ as the speed with which inflation returns to baseline after a deviation. The intuition behind this is that if $\rho$ is relatively high (close to unity), during high inflationary regimes inflation will be stubbornly high, while during periods of low inflation, a highly persistent inflation time series will result in consistently low values of inflation (Vladova-Pachedjiev 2008, Dossche-Everaert 2005, Vaona-Ascari 2012).

However, if the absolute value of the parameter $\rho$ is less than 1 , then the inflation series is broadly stationarity and returns to its mean. If $\rho$ is close to 0 , the speed of adjustment of the inflation series to its long-run trend is high. Dossche and Everaert (2005) notes that for values $\rho=0.5$ and below, the inflation series is considered to have a relatively low persistence. Járosi (2017) suggests the use of spatial econometric methods to neutralise all the previously discussed bias sources.

We cannot adopt spatial econometrics since the three regions in our study are geographically far from each other. The appropriate choice of lag length is crucial for the ADF tests, as using different information criteria produces varying lag lengths which heavily influences the behaviour of the point estimate for $\rho$. Vladova

Regional Statistics, Vol. 10. No. 2. 2020: 95-116; DOI: 10.15196/RS100211 
and Pachedjiev (2008) suggest that an ADF test can be conducted with an automatic selection of lag length (e.g., Akaike information criteria or Schwartz information criteria).

It is noteworthy that persistence cannot be measured without knowledge of the long-run path of a stationarity inflation time series, represented by the mean. As pointed out by Alberola and Marques (2000) and Marques (2004), deviations from this long-run path provide the basis for evaluating the persistence of a series. Thus, to gauge the behaviour of a region's inflation in response to a shock, we must know the path inflation would have taken had the shocks not occurred.

Observing the long-run path reveals that changes in the mean are common due to structural breaks (i.e., change in monetary policy regime, significant events). Failing to account for changes in the mean of the series could produce biased estimates of $\rho$. Hence, assuming a constant mean implies that the series is insensitive to structural changes in the mean of inflation or to possible changes in the persistence parameter itself. Spatial imteractions and spillover effects also determine the magnitude of convergence speed (Tánczos-Egri 2018).

\section{Empirical results}

The procedures outlined in the previous section are applied to test the inflation rates using national and regional level data. The regional data cover Medan, Makassar, and Jakarta (as explored by Arimurti-Trisnanto 2011), each chosen to represent western, eastern, and the capital regions of Indonesia, respectively. Both Medan and Makassar provinces have the highest non-oil and gas GDP contributions and are the most developing regions outside Java (BPS 2019). Jakarta is the nation's capital. Different from Purwono, Yasin, and Mubin (2020) who used all 82 cities in the panel to analyse price convergence, we use only three prominent regions to assess the price convergence in each city. Eventually, they are expected to explain the fluctuation of the inflation rate at the national level.

The chosen dimensions on which groups differ is month-year, respectively. This study captures data on monthly inflation rates from January 2001 to December 2018. The January 2001 period is set as the beginning of observation related to the implementation of regional authonomy and fiscal decetralisation policy. The total observations include 216 sample points for each region. The inflation rates are based on the relative changes in monthly consumer price index comprising hundreds of goods and services. They are stated in percentage. All of the data are taken from the Central Agency of Statistics.

Table 1 summarises the inflation rates in the three selected cities in Indonesia. Overall, the average monthly inflation rate in Medan (0.58) is the highest among the three cities, even at the national level (0.55). Its volatility, represented by the 
coefficient of variance $(\mathrm{CV})$ - standard deviation to mean ratio - is also the highest (1.9382 compared to 1.4305 as a benchmark).

When we divide them into pre- and post-IT adoption, the conclusion is the same. The average mean inflation rates are lower but are more volatile. Given this analysis, we infer that IT adoption is successful in reducing the magnitude of regional inflation rates, unlike the result of the study by Kusuma (2013). This is further detailed using statistical devices.

Table 1

Statistic descriptive of inflation rates, January 2001 to December 2018

\begin{tabular}{l|r|r|r|r}
\hline & Medan & Jakarta & Makassar & Indonesia \\
\hline Mean & 0.5862 & 0.5319 & 0.5382 & 0.5517 \\
Median & 0.4950 & 0.3900 & 0.4100 & 0.4350 \\
Maximum & 11.8900 & 7.9300 & 9.4400 & 8.7000 \\
Minimum & -1.3600 & -0.4100 & -1.7400 & -0.4500 \\
Std. Dev. & 1.1361 & 0.7340 & 0.9937 & 0.7892 \\
CV & 1.9382 & 1.3798 & 1.8463 & 1.4305 \\
Skewness & 4.6650 & 5.3294 & 3.6214 & 5.5531 \\
Kurtosis & 46.7058 & 50.1625 & 31.7347 & 54.5817 \\
Observations & 216 & 216 & 216 & 216
\end{tabular}

Source: Central Agency of Statistics (processed).

Does the regional monthly inflation rate performance apply for annual aggregation? Figure 1 presents the configuration of annual inflation rates in three selected cities and the national level over the last decade. It is observed that regional and national inflation rates are not far enough from each other, although the year 2005 is an exception. The annual inflation rate differential is substantial primarily in Medan. After the steep increase in oil prices, the inflation rate was remarkably high. Thus, we can say that the regional inflation rate is more sensitive to economic shocks than that of the national level.

It is noted that there is no significant difference in inflation rates between preand post-IT adoption. The pattern is highly synchronised implying that the three inflation rates are close to each other. The coefficient of correlation is high, 0.88 is the average. Again, it seems that the IT adoption has not yet stabilised the prices fluctuation both at regional and national levels.

Regional Statistics, Vol. 10. No. 2. 2020: 95-116; DOI: 10.15196/RS100211 
Annual inflation rates in the three selected regions and Indonesia

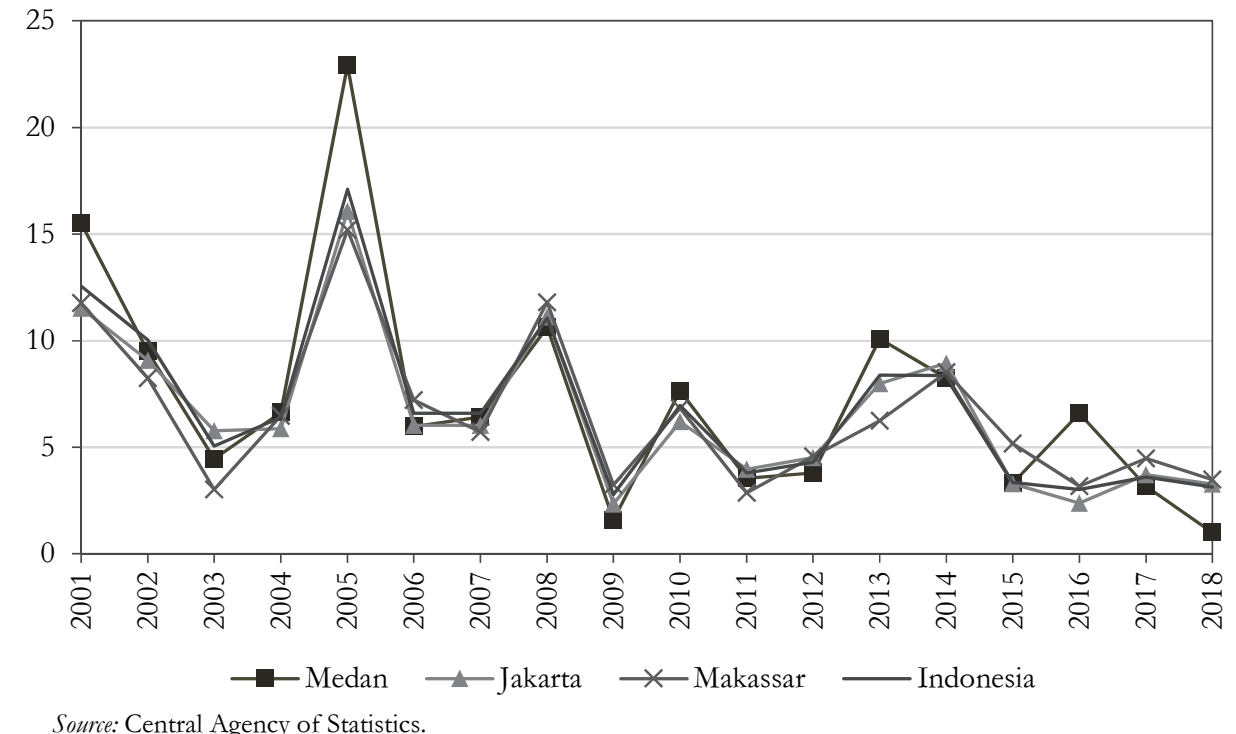

Table 2 presents the correlation matrix of the regional monthly inflation rates among three regions and the national level. The correlation coefficient between Jakarta and Indonesia is the highest both in the pre- and post-IT (0.92 and 0.96 respectively). It means that the inflation rate fluctuation in Jakarta is the most representative on the national level. Therefore, paying more attention to Jakarta is necessary in order to maintain the national inflation rate. This finding is consistent with Arimurti and Trisnanto (2011) and Winkelried and Gutierrez (2015). This evidence supports the view that by targeting Jakarta's inflation, the central bank has effectively, albeit indirectly, targeted national inflation.

Table 2

\section{Correlation matrix of inflation rates}

Pre- and post-IT

\begin{tabular}{l|c|c|c|c}
\hline & Medan & Jakarta & Makassar & Indonesia \\
\hline Medan & 1.0000 & 0.8167 & 0.7434 & 0.8800 \\
Jakarta & 0.6091 & 1.0000 & 0.8495 & 0.9688 \\
Makassar & 0.5572 & 0.6958 & 1.0000 & 0.8931 \\
Indonesia & 0.7517 & 0.9273 & 0.7795 & 1.0000
\end{tabular}

Note: the highlighted cells show the coefficient of correlation for the post-IT.

Table 3 breaks down the comparison of the regional monthly inflation rates for each year and month. By employing the two-way analysis of variance, the test 
proves that there is no significant difference in monthly inflation rates across regions and among subnational and national regions. These results are consistent with the correlation matrix, as presented in Table 2, since the coefficient of correlation is stronger for all cases.

In contrast, the difference in monthly inflation rates across the month is statistically significant at 1 per cent confidence level. Similarly, the difference in monthly inflation rates across the year exists at the same confidence level. These findings are consistent with the graph presented in Figure 1. The difference in monthly inflation rates may be attributed to the difference in seasonal inflation in each region over a year. Similar patterns are found for inflation rates across a year per economic cycles.

Table 3

Two way analysis of variance inflation rate in three selected cities and Indonesia, January 2001 to December 2018

\begin{tabular}{l|l|r|r|r|c}
\hline \multicolumn{7}{c}{ Tests of between-subjects effects } \\
\hline \multirow{2}{*}{\multicolumn{2}{c|}{ Source }} & \multicolumn{1}{c|}{$\mathrm{df}$} & $\begin{array}{c}\text { Mean } \\
\text { square }\end{array}$ & $\mathrm{F}$ & Sig. \\
\hline \multirow{2}{*}{ Region } & Hypothesis & 1 & 38.94 & 1.514 & 0.219 \\
\cline { 2 - 6 } & Error & 431 & 25.71 & & \\
\hline \multirow{2}{*}{ State } & Hypothesis & 1 & 4.98 & 0.188 & 0.668 \\
\cline { 2 - 6 } & Error & 26,717 & 26.42 & & \\
\hline \multirow{2}{*}{ Month } & Hypothesis & 11 & 412.09 & 3.994 & 0.000 \\
\cline { 2 - 6 } & Error & 59,716 & 103.19 & & \\
\hline \multirow{2}{*}{ Year } & Hypothesis & 17 & 216.87 & 2.370 & 0.005 \\
\cline { 2 - 6 } & Error & 88,393 & 91.50 & &
\end{tabular}

The two-way ANOVA cannot incorporate additional attribute IT as it is limited for two dimensions only. Table 4 and 5 comprehensively compares the regional and national monthly inflation rates data using multivariate analysis of variance with the IT regime as a covariate. We infer that a significant difference in monthly inflation rates across the month and the year exist at both the regional and national levels. It holds for all types of tests, including Wilks, Hotelling, Pillai-Bartlet, and Roy criterion, thus supports the previous analysis.

Advanced analysis of the IT regime gives a different conclusion. As displayed in Table 5, the IT adoption does not differ across the monthly inflation rate both at the regional and the national level. The exception is applied in the case of Medan. In the latter, the monthly inflation rates across a month substantially differ over a year. The highest mean value of monthly inflation rate and CV in Medan, as explained in Table 1, could be a explanation.

Regional Statistics, Vol. 10. No. 2. 2020: 95-116; DOI: 10.15196/RS100211 
Multivariate analysis of variance of inflation rate in three selected cities and Indonesia, January 2001 to December 2018

\begin{tabular}{ll|c|c|c|c|c}
\hline \multicolumn{7}{c}{ Multivariate tests } \\
\hline Effect & & Value & F & Hypothesis & Error & Sig. \\
\hline \multirow{4}{*}{ Month } & Pillai's Trace & 0.072 & 4.082 & 4.00 & 209.00 & 0.003 \\
\cline { 2 - 7 } & Wilks' Lambda & 0.928 & 4.082 & 4.00 & 209.00 & 0.003 \\
\cline { 2 - 7 } & Hotelling's Trace & 0.078 & 4.082 & 4.00 & 209.00 & 0.003 \\
\cline { 2 - 7 } Year & Roy's Largest Root & 0.078 & 4.082 & 4.00 & 209.00 & 0.003 \\
\cline { 2 - 7 } & Pillai's Trace & 0.046 & 2.542 & 4.00 & 209.00 & 0.041 \\
\cline { 2 - 7 } & Wilks' Lambda & 0.954 & 2.542 & 4.00 & 209.00 & 0.041 \\
\cline { 2 - 7 } IT & Hotelling's Trace & 0.049 & 2.542 & 4.00 & 209.00 & 0.041 \\
\cline { 2 - 7 } & Roy's Largest Root & 0.049 & 2.542 & 4.00 & 209.00 & 0.041 \\
\cline { 2 - 7 } & Pillai's Trace & 0.019 & 0.996 & 4.00 & 209.00 & 0.411 \\
\cline { 2 - 7 } & Hotelling's Trace & 0.981 & 0.996 & 4.00 & 209.00 & 0.411 \\
\cline { 2 - 7 } & Roy's Largest Root & 0.019 & 0.996 & 4.00 & 209.00 & 0.411 \\
\hline
\end{tabular}

Multivariate analysis of variance of month-year inflation rate in three selected cities and Indonesia, January 2001 to December 2018

\begin{tabular}{|c|c|c|c|c|c|c|}
\hline \multicolumn{7}{|c|}{ Tests of between-subjects effects } \\
\hline Source & $\begin{array}{l}\text { Dependent } \\
\text { Variable }\end{array}$ & $\begin{array}{l}\text { Type III } \\
\text { Sum of } \\
\text { squares }\end{array}$ & df & Mean square & $\mathrm{F}$ & Sig. \\
\hline \multirow[t]{4}{*}{ Month } & Medan & 985.00 & 1 & 985.00 & 8.233 & 0.005 \\
\hline & Jakarta & 40.03 & 1 & 40.03 & 0.767 & 0.382 \\
\hline & Makassar & 22.49 & 1 & 22.49 & 0.244 & 0.622 \\
\hline & Indonesia & 80.33 & 1 & 80.33 & 2.712 & 0.101 \\
\hline \multirow[t]{4}{*}{ Year } & Medan & 770.69 & 1 & 770.69 & 6.441 & 0.012 \\
\hline & Jakarta & 478.97 & 1 & 478.97 & 9.184 & 0.003 \\
\hline & Makassar & 469.76 & 1 & 469.76 & 5.106 & 0.025 \\
\hline & Indonesia & 211.14 & 1 & 211.14 & 7.130 & 0.008 \\
\hline \multirow[t]{4}{*}{ IT } & Medan & 197.51 & 1 & 197.51 & 1.651 & 0.200 \\
\hline & Jakarta & 118.61 & 1 & 118.61 & 2.274 & 0.133 \\
\hline & Makassar & 356.29 & 1 & 356.29 & 3.873 & 0.050 \\
\hline & Indonesia & 20.96 & 1 & 20.96 & 0.708 & 0.401 \\
\hline
\end{tabular}

We found that statistically there is no significant difference in monthly inflation rates in the period of pre- and post-IT adoption. These results confirm the previous analysis that the monetary policy is only effective on the national scope. In the lower layers, in this case sub-national, the monetary policy would be ineffective unless some specific aspects embodied in each region are considered. Therefore, to 
solve these issues, a strong commitment from the leaders of these regions and the availability of accurate data are the necessities for exploring cooperation between regions.

As the regional inflation rates are typically generated by supply-side (Tirtosuharto-Adiwilaga 2013), the leaders of the regions need four strategic measures to maintain regional control or the ' $4 \mathrm{~K}$ ' (in Indonesian: Ketersediaan, Keterjangkauan, Kelancaran, Komunikasi), namely supply availability, price affordability, distribution smoothness, and expectation communication (Governor of Bank Indonesia 2014). Accordingly, certain institutional aspects reduce the disparity of regional inflation. Thus, monetary methods alone were ineffective in controlling inflation and recommendations were made for improving regional anti-inflationary policies.

Next, we focus on the time series properties of each series. Each series is examined twice using ADF unit-roots test for pre- and post-IT regimes to ensure that all of the components are stationarity. We assume that the underlying data are non-stationarity. Both tests conclude that all the variables are not entirely stationarity in their level. Hence, the ADF tests are applied again to the transformed series of each variable to check for the possibility of stationarity in the first differences.

The results concerning the stationarity of the variable of interest are reported in Table 6 . The tests confirm the stationarity of all series on the first difference. In other words, in the first-difference forms, all the variables become stationarity. Overall, the structural break arosed around the year 2005 when the oil prices were increased by the government to repress the fiscal burden on the energy subsidy.

Table 6

Unit-roots tests

\begin{tabular}{l|c|c|c|c|c|c}
\hline \multirow{2}{*}{} & \multicolumn{2}{|c|}{ Pre-IT } & \multicolumn{2}{c|}{ Post-IT } & \multicolumn{2}{c}{ Total } \\
\cline { 2 - 7 } & Coeff. & Breakpoint & Coeff. & Breakpoint & Coeff. & Breakpoint \\
\hline Medan & -6.7838 & $2002 \mathrm{M} 03$ & -9.1376 & $2007 \mathrm{M} 01$ & -12.5699 & $2005 \mathrm{M} 10$ \\
Jakarta & -5.5715 & $2002 \mathrm{M} 04$ & -10.6336 & $2014 \mathrm{M} 12$ & -12.0525 & $2005 \mathrm{M} 10$ \\
Makassar & -7.8763 & $2002 \mathrm{M} 02$ & -10.4877 & $2006 \mathrm{M} 11$ & -11.4231 & $2005 \mathrm{M} 10$ \\
Indonesia & -5.4556 & $2002 \mathrm{M} 02$ & -8.8270 & $2008 \mathrm{M} 09$ & -11.4154 & $2005 \mathrm{M} 10$
\end{tabular}

The null hypotheses of non-stationarity can be rejected, which does not demonstrate the existence of a trend in the series. All the variables were found to be stationarity at 1 percent significance level implying that the series data have unitroots and the behaviour of the variables fluctuates around the mean value and are invariant overtime (Enders 2004). The occurrence of unit-roots in the series gives a preliminary indication of shocks having a permanent or long-lasting effect, thus making it difficult for traditional stabilisation policies to survive.

Regional Statistics, Vol. 10. No. 2. 2020: 95-116; DOI: 10.15196/RS100211 
Table 7 reports the ordinary least squares (OLS) estimation results of the four models specified in the previous section. We start with the simple model directly connecting the growth rates of consumer price index (CPI) and the past value based on the Akaike and Schwartz information criteria. In the period of pre-IT adoption, the corresponding coefficient is insignificant in the case of Makassar, i.e. random walk phenomenon, suggesting dynamic instability. In other cases, the coefficient is statistically significant at the 1 percent confidence level. They suggest that past inflation rates adjust to the current inflation rate up to approximately 76-92 percent.

Estimation of the same model for the period of post-IT adoption offers similar coefficients. The speed of adjustment, in general, is slightly higher, except in the case of Medan. However, this test speed of adjustment in all cases is high, about 80 percent, to achieve the intended rate of inflation. This supports the result supplied by ANOVA. We infer that IT adoption successfully reduces the magnitude of the regional inflation rates instead of its volatility.

During the period of observation, the inflation persistence, considered as a measure of the degree of dependence on the current behaviour based on the past developments, ranges from 0.14 to 0.24 , implying that only 14 to 24 percent is partial-adjusted. The higher coefficient of the speed of adjustment for Makassar and Medan support Purwono, Yasin, and Mubin (2020). In other words, the regional inflation rate tends to be less persistent than the national data. This result supports the conventional wisdom that national inflation data is less persistent than the regional data.

Our findings of the low inflation persistence are similar to the findings of Kundu, Kishore, and Bhoi (2018). However, our study challenges Tillmann (2013). The empirical results in Table 7 show that the adoption of IT does not lead to a reduction in the cross-regional heterogeneity in inflation persistence. The underlying cross-sectional factors (e.g. geography, income development among others) could insignificantly influence the different regions' inflation processes, which confirm the results of multivariate ANOVA above.

Table 7

Estimation results of speed of adjustment

\begin{tabular}{l|r|r|r}
\hline & Pre-IT & Post-IT & Total \\
\hline Medan & 0.9474 & 0.8323 & 0.8515 \\
Jakarta & 0.7499 & 0.8313 & 0.8104 \\
Makassar & - & 0.8870 & 0.9219 \\
Indonesia & 0.7347 & 0.7721 & 0.7590
\end{tabular}

Note: All coefficients are significant at 99 percent confidence level. 


\section{Robustness check}

Furthermore, the lagged dependent variable in the estimation model is not entirely significant, indicating that our estimated inflation rate model is not well specified. Next, it is necessary to check the stability of the inflation rate function, as it is necessary for an effective monetary policy. Therefore, it has to be tested whether the estimated inflation rate equation has shifted over time.

Moreover, the estimation results presented in Table 7, primarily in Makassar violate some classical assumptions. Re-estimating the basic model using OLS with breakpoints suggests that structural break exists around the mid-2000s, as found in the unit-roots test. Besides the OLS estimators are sensitive to the presence of observations that lie outside the norm of the regression model of interest.

The sensitivity of conventional regression methods to these outlier observations may result in coefficient estimates that do not accurately reflect the underlying statistical relationship. Altissimo, Ehrmann, and Smets (2006) distinguished three basic sources of inflation persistence: one that is inherited from persistent fluctuations in the determinants of inflation (extrinsic persistence); the dependence of inflation on its past (intrinsic persistence); and persistence due to the formation of inflation expectations (expectations-based persistence). Therefore, it is necessary to conduct robustness tests.

We use the cumulative sum (CUSUM) tests as a measure of robustness measure for empirical results, to test for the stability of the model. CUSUM stands for cumulative summation of recursive residual generated by the regression equation. If the CUSUM values are within the tolerated lower and upper bands, the regression function is said to have a constancy of parameter regression.

As shown in Figure 2, CUSUM falls within the 95 percent confidence band, which verifies the stability of estimated parameters in all cases, meaning that they do not change overtime. Overall, the three regional and the national inflation rates have a stable function further implying that it can be used for prediction and policy simulation purposes.

Another robustness approach is by including a dummy variable for the global financial crisis (Delbianco et al. 2019) in the models as a control variable for external shocks. It is noted that this does not affect the magnitude and significance of our estimators, indicating the earlier models encompasses to the current models. However, comparing the pre- and post-IT regime, the results support the presence of failure effects of IT on the volatility of the inflation rates reduction in the fiscal decentralisation era.

Regional Statistics, Vol. 10. No. 2. 2020: 95-116; DOI: 10.15196/RS100211 


\section{CUSUM of robustness tests}
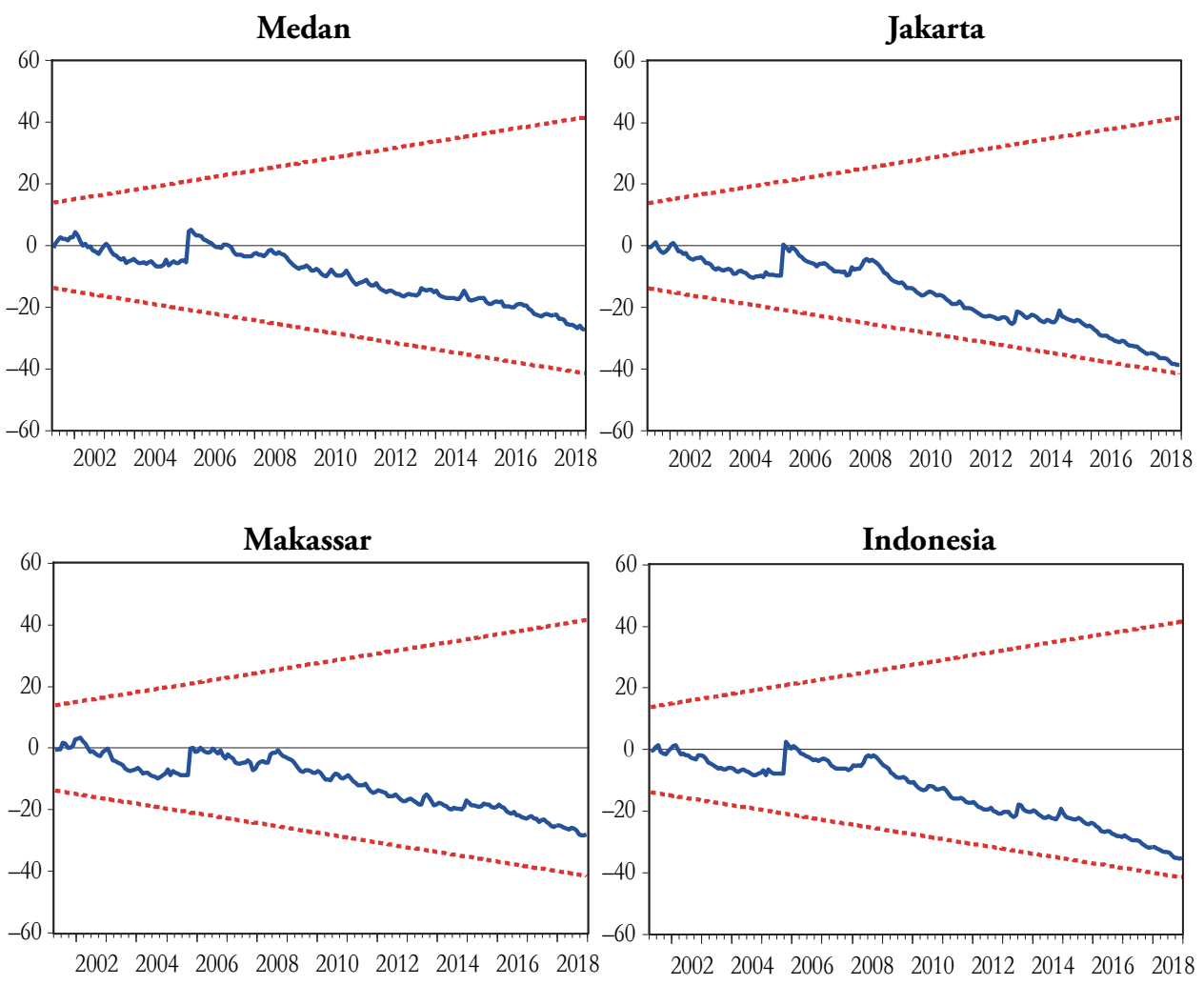

- CUSUM

--- $5 \%$ significance

\section{Concluding remarks}

The main objective of this paper is to identify the regional inflation persistence and the speed of adjustment in the case of three selected cities and the country as a whole. This research is motivated by the empirical result that the IT adoption can reduce the persistence of inflation fluctuations, it is derived from aggregate inflation or sectoral inflation rates. However, the opposite conclusion is based on regional inflation data.

Unlike other studies, we compare them in the pre- and post-IT adoption with July 2005 as the breaking time. We also compare them to the national level. In this study, we used monthly inflation data from January 2001 to December 2018 published by the Central Agency of Statistics. Using the analysis of variance, we found that the monthly inflation rates in Medan, Jakarta, Makassar, and Indonesia vary within a month but are stable over the year. Employing standard time series 
econometric procedures, we found that there is low inflation rate persistence and therefore a high speed of adjustment. The speed of adjustment is found to be slightly higher in the post-IT adoption.

However, the stability tests of the parameter constancy present that there is no significant difference between the pre- and post-IT adoption. It implies that IT adoption has not yet changed the inflation persistence neither at national nor subnational levels, suggesting weak coordination among the monetary authority, the fiscal authority, the RITF, and regions (local governments) in controlling regional price levels. This indicates that the local authority must focus on the short-term regional price fluctuations, while the monetary authority should be concerned with the long-term national price fluctuations. Therefore, the economic policy should consider the local wisdom to overtake related problems. Accordingly, a common inflation rate cannot be achieved uniformly for each region. As the regional inflation rate is typically generated by supply-side, the results suggest that managing interregion cooperation in the supply-chain will foster stability and reduce the national inflation rate. Indeed, price level stabilisation in the regional autonomy and fiscal decentralisation era is one of the greatest obstacles for any economy in the world.

\section{REFERENCES}

Alagidede, P.-Coleman, S.-ADU, G. (2014): A Regional analysis of inflation dynamics in Ghana: Persistence, Causes and Policy Implications IGC Working Paper, October 2014., London.

Alberola, E.-MARQues, J. (2000): On the nature and relevance of inflation differentials in Spain Banco de España Research Paper No. WP-9913., Madrid.

ALM, J.-BAHL, R. W.-ATEN, R. H. (2001): Can Indonesia decentralise successfully? Plans, problems and prospects Bulletin of Indonesian Economic Studies 37 (1): 83-102. https://doi.org/10.1080/000749101300046537

ALtissimo, F.-EHRMANN, M.-SMETS, F. (2006): Inflation persistence and price setting behaviour in the Euro Area - a summary of the IPN evidence European Central Bank Occasional Paper Series No. 46 (June, 2006), ECB, Frankfurt am Main.

Arimurti, T.-Trisnanto, B. (2011): Persistence of inflation in Jakarta and its implication on the regional inflation control policy Bulletin of Monetary Economics and Banking 14 (1): 5-30. https://doi.org/10.21098/bemp.v14i1.76

Auer, R. A.-LevchenkO, A.-SAuré, P. (2017): International inflation spillovers through input linkages NBER Working Paper 23246, National Bureau of Economic Research, Cambridge, MA. https://doi.org/10.1162/rest_a_00781

BALASSA, B. (1964): The purchasing power parity doctrine: A reappraisal Journal of Political Economy 72 (6): 584-96. https://doi.org/10.1086/258965.

Barro, R. J.-SALA-I-MARTIN, X. (1995): Economic growth McGraw-Hill Book Co. Inc., New York.

Regional Statistics, Vol. 10. No. 2. 2020: 95-116; DOI: 10.15196/RS100211 
Beck, G.-Hubrich, K.-MARCELlinO, M. (2006): Regional inflation dynamics within the Euro Area Countries and a comparison with the US ECB Working Paper Series, No. 681, October, Frankfurt am Main.

BECKER, S. S. (2011): What drives the relationship between inflation and price dispersion? Market Power vs. Price Rigidity SFB 649 Discussion Paper 2011-019., Humboldt University, Berlin.

BPS (2019): Produk domestik regional bruto menurut provinsi 2010-2018, seri 2010 BPS, Jakarta.

Brodjonegoro, B. (2004): The Indonesian decentralization after law revision: Toward a better future? Paper presented at the International Symposium on Fiscal Decentralization in Asia Revisited, Tokyo, Japan.

Ciccarelli, M.-Mojon, B. (2010): Global inflation Review of Economics and Statistics 92 (3): 524-535.

DanveE N. F.-BAsilio, J. R. (2009): Regional inflation persistence in the Philippines Bangko Sentral Review: 41-54.

Delbianco, F.-Fioriti, A.-Tohmé, F. (2019): Quantifying worldwide economic distress Regional Statistics 9 (1): 3-12. https://doi.org/10.15196/RS090108

Dossche, M.-Everaert, G. (2005): Measuring inflation persistence: A structural series approach National Bank of Belgium, Brussels.

ENDERS, W. (2004): Applied econometric time series Second edition, John Wiley \& Sons, New York.

GOVERNOR OF BANK INDONESIA (2014): Speech in the national coordination Meeting V of Regional Inflation Control Team, 21 May 2014, in Jakarta

http://www.bi.go.id/en/ruang-media/siaran-pers/Pages/sp_163414.aspx. (downloaded: May 2020)

HAKKIO, C. S. (2009): Global inflation dynamics Research Working Papers 09-01, Federal Reserve Bank of Kansas City, Kansas City, MO.

Hossain, A. A. (1996): Monetary and financial policies in developing countries: Growth and stabilization Routledge, London.

JÁROSI, P. (2017): Modelling network interdependencies of regional economies using spatial econometric techniques Regional Statistics 7 (1): 3-16. https://doi.org/10.15196/RS07101

KOCZISZKY, GY.-BENEDEK, J.-SZENDI, D. (2018): The impact of the 2008 financial crisis on household income and wealth in Visegrad countries Regional Statistics 8 (1): 141-167. https://doi.org/10.15196/RS080102

Krugman, P.-ObSTFELD, M. (2000): International economics, theory and policy Fifth edition, Addison-Wesley Publishing Company, Boston.

Kundu, S.-KISHORE, S. V.-BHOI, S. B. B. (2018): Regional inflation dynamics in India RBI Bulletin 40 (1): 57-66.

KusumA, IGP. W. (2013): The Dynamics of Indonesian inflation: What can we learn from inflation disaggregation? Bulletin of Monetary Economics and Banking 16 (1): 43-79. https://doi.org/10.21098/bemp.v16i1.437

MARQUES, C. (2004): Inflation persistence: facts or artefacts? ECB Working Paper Series, No. 371, June 2004., Frankfurt am Main.

Regional Statistics, Vol. 10. No. 2. 2020: 95-116; DOI: 10.15196/RS100211 
Mehrotra, A.-Peltonen, T.-Rivera, A. (2007): Modeling Regional Inflation in China: A Regional Perspective ECB Working Paper Series No. 829, November, Frankfurt am Main.

Mohanty, M. S.-KLAU, M. (2001): Fiscal decentralization in developing countries: Is it happening? How do we know? Bank for International Settlements Working Paper No. 8., Basel.

Mundell, R .A. (1961): A theory of optimum currency areas American Economic Review 51 (4): 657-665.

Prud'Homme, R. (1995): On the danger of decentralization World Bank Research Observer 10 (2): 201-220.

PurwonO, R.-YAsin, M. Z.-Mubin, M. K. (2020): Explaining regional inflation programmes in Indonesia: Does inflation rate converge? Economic Change and Restructuring (in press) https://doi.org/10.1007/s10644-020-09264-x

Rogoff, K. (1996): The purchasing power parity Puzzle Journal of Economic Literature 34 (2): 647-668.

SAmuelson, P. A. (1964): Theoretical notes on trade problems Review of Economics and Statistics 46 (2): 145-154. https://doi.org/10.2307/1928178.

SEPulvedA, C. F.-MARTINEZ-VAZQUEZ, J. (2010): The consequences of fiscal decentralization on poverty and income inequality international studies program, Working Paper 10-02. Andrew Young School of Policy Studies, Georgia State University, Atlanta.

SVENSSON, L. O. (1999): Inflation targeting as a monetary policy rule Journal of Monetary Economics 43 (3): 607-654. https://doi.org/10.1016/S0304-3932(99)00007-0

SVENSSON, L. O. (2000): Open-economy inflation targeting Journal of International Economics 50 (1): 155-183. https://doi.org/10.1016/S0022-1996(98)00078-6

TABACHNICK, B. G.-FIDELL, L. S. (2007): Using multivariate statistics Harper Collins College Publishers, New York.

TÁnCZOS, T.-EGRI, Z. (2018): The spatial peculiarities of economic and social convergence in Central and Eastern Europe Regional Statistics 8 (1): 49-77. https://doi.org/10.15196/RS080108

Tillmann, P. (2013): Inflation targeting and regional inflation persistence: Evidence from Korea Pacific Economic Review 18 (2): 147-161. https://doi.org/10.1111/1468-0106.12016

Tirtosuharto, D.-Adiwilaga, H. (2013): Decentralization and regional inflation in Indonesia Bulletin of Monetary Economics and Banking 6 (2): 149-166. https://doi.org/10.21098/bemp.v16i2.30

Tunay, B. K.-SIlPAgAR, A. M. (2007): Regional inflation convergence analysis in Turkey with dynamic space-time panel data models Periodical of Gazi University Faculty of Economics and Administrative Sciences 9 (1): 206-218.

VAONA, A. (2008): A cross-sectional approach to regional long-run inflation in Italy Faculty of Economic Sciences, University of Lugano, Lugano.

VAONA, A.-AsCARI, G. (2012): Regional inflation persistence: Evidence from Italy Regional Studies 46 (4): 509-543. https://doi.org/10.1080/00343404.2010.505913

VLADOVA, Z.-PACHEDJIEV, S. (2008): Empirical analysis of inflation persistence and price dynamics in Bulgaria Bulgarian National Bank Working Paper, Sofia.

Regional Statistics, Vol. 10. No. 2. 2020: 95-116; DOI: 10.15196/RS100211 
WEBER, A. A. (2004): European inflation dynamics and inflation convergence, open macro models and policy in the development of European Economy Paper Presented at Conference at the European University Institute, 15 October, Florence.

WILLIS, J. (2003): Implications of structural changes in the US economy for pricing behavior and inflation dynamics Economic Review, Federal Reserve Bank of Kansas City 88 (Q I): $5-27$.

Winkelried, D.-GutierreZ, J. E. (2015): Regional inflation dynamics and inflation targeting, the case of Peru Journal of Applied Economics 18 (2): 199-224. https://doi.org/10.1016/S1514-0326(15)30009-X

ZsıBÓK, Z. (2017): Continuing divergence after the crisis: Long-term regional economic development in the United Kingdom Regional Statistics 7 (1): 17-42. https://doi.org/10.15196/RS07102 